\title{
Composição Corporal e Exigências Líquidas de Proteína e Energia para Ganho de Peso de Bezerros Machos de Origem Leiteira do Nascimento aos 110 Dias de Idade ${ }^{1}$
}

\author{
Paulo Afonso Carvalho ${ }^{2}$, Luis Maria Bonnecarrère Sanchez ${ }^{3}$, Cleber Cassol Pires ${ }^{3}$, \\ Julio Viégas ${ }^{3}$, João Pedro Velho ${ }^{4}$, Wagner Paris ${ }^{5}$
}

\begin{abstract}
RESUMO - O presente estudo foi conduzido para avaliar a composição corporal e determinar as exigências líquidas de proteína e energia para ganho de peso de bezerros de origem leiteira, no início da vida produtiva. Foram usados 18 bezerros da raça Holandês, machos, não castrados, do nascimento até os 110 dias de idade, pesando entre 30 e $100 \mathrm{~kg}$. Seis animais foram abatidos no início do experimento (ao nascimento). Outros doze animais foram alimentados à vontade até atingirem a idade pré-estabelecida de abate. Seis animais foram abatidos quando completaram 50 dias e seis quando completaram 110 dias de idade. Foram ajustadas equações de regressão do logaritmo da quantidade corporal de proteína, gordura e energia, em função do logaritmo do peso corporal vazio (PCVZ). As exigências líquidas de proteína e energia para ganho de peso foram obtidas por derivação das equações de predição da composição corporal. O conteúdo corporal de proteína, gordura e energia elevou-se à medida que aumentou o PV. Os requerimentos líquidos de proteína e energia para ganho de peso corporal vazio (GPCVZ) cresceram quando o PCVZ variou de 27,57 até 74,27 kg. Os valores líquidos requeridos variaram de 200,60 a 229,21 g/kg GPCVZ para proteína e de 1,93 a 2,99 Mcal/kg GPCVZ para energia.
\end{abstract}

Palavras-chave: Holandês, peso corporal vazio, peso vivo, requisitos nutricionais

\section{Body Composition and Net Protein and Energy Requirements for Weight Gain of Dairy Male Calves at Newly Born to 110 Days of Age}

\begin{abstract}
The work was carried out to evaluate the body composition and the net requirements of protein and energy for weight gain of dairy calves in the beginning of the productive life were determined. Eighteen Holstein bulls calves at newly born to 110 days of age weighing between 30 and $100 \mathrm{~kg}$ were used. Six animals were slaughtered at the beginning of the experiment (to birth) and other twelve animals were full fed until a pre-established slaughter of age. Six animals were slaughtered when completed 50 days and six when completed 110 days of age. Regression analysis of the logarithm of protein, fat and energy corporal amount in function of the empty body weight (EBW) logarithm were fitted. The net requirements of protein and energy for weight gain were obtained by derivation of the prediction equations of corporal composition. The body content of protein, fat and energy increased in according to the LW increase. The net requirements of protein and energy for empty body weight gain (EBWG) increased as the empty body weight changes from 27.57 to $74.27 \mathrm{~kg}$. The net requirements changed from 200.60 to $229.21 \mathrm{~g} / \mathrm{kg}$ EBWG for protein, from 1.93 to 2.99 Mcal/kg EBWG for energy.
\end{abstract}

Key Words: empty body weight, holstein, live weight, nutritional requirements

\section{Introdução}

O crescimento de um bezerro compreende transformações no tamanho e estrutura do seu corpo, que acontecem no início da vida. Implica na construção de tecidos novos nos ossos, músculos e órgãos. Essa construção ocorre principalmente graças à deposição de proteínas, minerais e água nas células e interstícios (Lucci, 1989).

O animal ganha peso pela acumulação de tecidos, segundo certos padrões de prioridade. Primeiro cres- cem intensamente as vísceras, seguidas pelo tecido ósseo, muscular e finalmente o tecido adiposo (Di Marco, 1994). Neste sentido, os componentes químicos do corpo variam durante o crescimento de forma paralela à composição física corporal (Véras et al., 2000).

A maturidade animal é refletida pelo aumento na proporção de gordura e decréscimos na proporção de água e de proteína no corpo (Berg \& Butterfield, 1976). À medida que se eleva o peso do animal, ocorre a desaceleração do crescimento muscular, acontecendo o contrário com o tecido adiposo. A

\footnotetext{
${ }^{1}$ Parte da Dissertação apresentada à Universidade Federal de Santa Maria (UFSM), pelo primeiro autor como um dos requisitos para obtenção do Título de Mestre em Zootecnia.

2 Zootecnista, M.Sc. Doutorando pela Universidade Federal de Lavras (UFLA). Bolsista CNPq. Rua Progresso, 41/801. Lavras, MG. 37200.000. Autor para correspondência. pac@ufla.br

3 Professor do Departamento de Zootecnia da UFSM, RS.

${ }^{4}$ Acadêmico de Zootecnia (UFSM) - Bolsista de iniciação científica CNPq.

5 Zootecnista, Mestrando em Zootecnia pela Universidade Estadual de Maringá (UEM), PR.
} 
composição corporal e do ganho estão intimamente relacionadas, sendo a segunda uma conseqüência da primeira. O estado de desenvolvimento influencia a composição do ganho, ou seja, animais mais desenvolvidos requerem mais energia para o ganho de peso (Di Marco, 1994).

A estimativa mais satisfatória da magnitude de um processo produtivo é obtida através do valor calórico do produto formado. A esta se denomina de exigência líquida de energia, e é independente do alimento requerido para satisfaze-la (Blaxter, 1964). Portanto, a energia líquida pode ser definida como a quantidade de energia apresentada como reserva da substância corporal ou como produto animal (Kleiber, 1972).

Outro nutriente essencial ao desenvolvimento animal é a proteína. Presente como principal componente dos órgãos e estruturas moles do organismo, deve ser suprida durante toda a vida, para o crescimento e desenvolvimento orgânico e corporal (Maynard et al., 1984). Conforme o NRC (1996), a proteína líquida para ganho de peso é aquela proteína que fica retida no organismo ou no corpo animal. Segundo Backes (1998), indivíduos jovens apresentam uma exigência protéica bastante elevada, por estarem em crescimento e, conseqüentemente, em fase de formação muscular, onde a proteína entra como o principal constituinte deste tecido.

De acordo com Signoretti et al. (1999), as diferenças nas exigências de energia para ganho de peso entre animais ocorrem devido a variações na composição do ganho de peso. A energia líquida requerida para o crescimento e ganho de peso dos animais corresponde ao valor calórico dos tecidos ou energia bruta da gordura e proteína depositadas no corpo.

Ferrel \& Jenkis (1998) relatam que a taxa de acréscimo de proteína é maximizada em determinada taxa de ganho de corpo vazio, com pouca ou nenhuma proteína adicional sob taxas de crescimento mais rápidas. O depósito de gordura, apesar de inicialmente crescente, atinge um platô máximo, a partir do qual se mantém relativamente constante aos incrementos de ganho.

Quando os animais saem da fase de crescimento e atingem a maturidade, verifica-se um incremento nas exigências energéticas e uma redução nos requerimentos protéicos, de acordo com o aumento de peso e mudanças ocorridas no ganho de peso corporal, como demonstrado nos experimentos conduzidos por Fontes (1995), Rocha (1997), Backes (1998), Almeida et al. (1999) e Véras et al. (2000).

Conforme Teixeira (1984), a composição corporal pode ser afetada pelo tipo genético, sexo, alimentação e taxa de crescimento. Entretanto, Fox \& Black (1984) citam que além desses fatores, também influenciam o peso e a taxa de ganho. $\mathrm{O}$ conhecimento da composição corporal de bovinos é necessário para estimar os requerimentos líquidos de nutrientes, os quais se distinguem em função de diferentes composições corporais. Este tipo de estudo ainda é deficiente no Brasil, principalmente com relação a bezerros machos de origem leiteira (Rocha \& Fontes, 1999). O volume de publicações sobre a composição corporal de animais nacionais, permitindo fazer estimativas de exigências nutricionais adequadas às nossas condições, ainda é muito incipiente (Araújo et al., 1998).

Relata Coelho da Silva (1995) que a eficiência na produção animal somente pode ser obtida se houver um conhecimento adequado das exigências nutricionais dos animais e da composição dos alimentos, evidentemente associados a outras práticas de manejo. No Brasil o cálculo de rações tem se baseado em normas norte americanas, conhecidas como boletins do "National Research Council” (NRC). Esses boletins são periodicamente adaptados para atender as necessidades diferenciadas dos EUA. No entanto, essas recomendações têm sido utilizadas no Brasil sem qualquer preocupação de examiná-las e adaptálas para as condições locais, devido às variações genéticas ou ambientais brasileiras.

O objetivo do presente estudo foi obter informações sobre exigências nutricionais em condições brasileiras, bem como determinar as exigências líquidas de proteína e energia para ganho de peso de bezerros Holandês na fase inicial da vida produtiva.

\section{Material e Métodos}

O estudo foi realizado no Setor de Nutrição Animal do Departamento de Zootecnia da Universidade Federal de Santa Maria, RS. Foram utilizados 18 bezerros da raça Holandês, machos, não castrados, dos quais seis foram abatidos ao nascimento, seis aos 50 dias e seis aos 110 dias de vida. Os animais sorteados para os grupos de abate aos 50 e 110 dias foram mantidos confinados em baias individuais até o dia do sacrifício. No início da segunda semana foi introduzido um concentrado contendo 18\% de PB. Também foi ofertado água e feno de alfafa (Medicago 
sativa) picado, ad libitum, a partir do início da segunda e terceira semana, respectivamente. O desaleitamento dos bezerros ocorreu gradativamente dos 28 aos 50 dias de vida.

Por ocasião do abate foram pesados e amostrados todos os constituintes corporais. O peso corporal vazio (PCVZ) foi obtido diretamente pelo somatório dos pesos de patas, cabeça, couro, sangue, órgãos, vísceras vazias, gordura interna e carcaça.

As carcaças foram resfriadas em câmara frigorífica a $2{ }^{\circ} \mathrm{C}$ por um período de 24 horas. Decorrido esse período, foi procedida a separação física total de osso, músculo e gordura em todas as $1 / 2$ carcaças esquerdas, assim como, nas patas e cabeça. Após, os diferentes tecidos foram triturados separadamente, sendo obtida uma amostra de osso e outra de tecido mole (músculo+gordura) da carcaça inteira + patas e cabeça para cada animal experimental.

As amostras de couro, órgãos+vísceras+gordura interna, tecido mole da carcaça inteira e osso da carcaça inteira foram pré-desengorduradas com éter de petróleo, conforme metodologia descrita por Kock \& Preston (1979). Após a determinação do teor de umidade e do pré-desengorduramento, as amostras foram moídas finamente e armazenadas em vidros para posteriores análises laboratoriais. O teor de gordura total da amostra foi obtido somando-se a gordura removida no pré-desengorduramento com o extrato etéreo residual. As amostras de sangue não foram pré-desengorduradas, apenas foi determinada a matéria pré-seca. Para tanto, as amostras foram colocadas em bandejas de alumínio e levadas à estufa a $55^{\circ} \mathrm{C}$ com circulação forçada de ar por 72 horas.

As determinações de matéria seca, nitrogênio total, extrato etéreo e cinzas foram realizadas segundo metodologias descritas por Silva (1990).

Os pesos absolutos dos componentes corporais (sangue, couro, órgãos + vísceras + gordura interna, tecido mole da carcaça e osso da carcaça) foram multiplicados pelos seus respectivos teores de matéria seca, proteína, gordura e cinzas. O somatório dos valores de composição química de cada componente corporal forneceu o valor total de cada nutriente e permitiu o cálculo do percentual da constituição no corpo vazio.

O conteúdo corporal de energia foi obtido a partir dos conteúdos de proteína e gordura retidos no corpo vazio e dos respectivos equivalentes calóricos, de acordo com a equação proposta pelo ARC (1980):

$$
\mathrm{CE}=5,6405 \mathrm{X}+9,3939 \mathrm{Y}
$$

em que: $\mathrm{CE}=$ Conteúdo de energia (Mcal); $\mathrm{X}=$
Proteína corporal (kg); Y= Gordura corporal (kg).

Para predição dos conteúdos de proteína, gordura e energia retidos no corpo dos animais, foi adotada a equação de regressão do logaritmo do conteúdo corporal de proteína, gordura e energia em função do logaritmo do peso de corpo vazio (PCVZ), de acordo com o modelo adotado pelo ARC (1980):

$$
\mathrm{y}_{\mathrm{ij}}=\mathrm{a}+\mathrm{b} \cdot \mathrm{X}_{\mathrm{ij}}+\mathrm{e}_{\mathrm{ij}} \text {, }
$$

em que: $y_{i j}=$ logaritmo de base 10 da quantidade do componente no corpo vazio; $\mathrm{a}=$ intercepto; $\mathrm{b}=$ coeficiente de regressão do logaritmo do conteúdo de proteína, gordura ou energia, em função do logaritmo do peso de corpo vazio; $\mathrm{X}_{\mathrm{ij}}=$ logaritmo do peso de corpo vazio; $\mathrm{e}_{\mathrm{Ij}}=$ erro aleatório.

Para conversão do peso vivo em peso de corpo vazio, utilizou-se a equação obtida por regressão do peso de corpo vazio dos 18 bezerros abatidos, em função do peso vivo ao abate dos mesmos. A faixa de peso vivo variou entre 30 e $100 \mathrm{~kg}$ com correspondentes pesos de corpo vazio variando de 27,57 a 74,27 kg.

Foi determinado um fator de conversão (FC) do PV em PCVZ para animais de diferentes pesos vivo, obtido pelo quociente do PV, em função do PCVZ dos animais, e este FC foi utilizado para converter o GPCVZ em GPV.

Derivando-se as equações logarítmicas de estimativa do conteúdo corporal de proteína, gordura e energia, foram obtidas as equações de predição das exigências líquidas de proteína e energia para ganho de $1 \mathrm{~kg}$ de PCVZ, do tipo:

$$
\mathrm{y}^{\prime}=\mathrm{b} \cdot 10^{\mathrm{a}} \cdot \mathrm{X}^{(\mathrm{b}-1)}
$$

em que: y’= exigência líquida de proteína (g/kg GPCVZ) e energia (Mcal/kg GPCVZ); b = coeficiente de regressão do logaritmo do conteúdo de proteína e energia em função do logaritmo de PCVZ; $\mathrm{a}=$ intercepto; $\mathrm{X}=$ PCVZ (kg).

As exigências líquidas em proteína e energia para ganho de peso vivo (GPV) foram obtidas dividindo-se os requerimentos de GPCVZ pelo FC obtido no presente estudo.

Os dados foram submetidos a análises de regressão para o estudo das variáveis, por intermédio do programa SAS (1996).

\section{Resultados e Discussão}

Os parâmetros das equações de regressão do logaritmo da quantidade de proteína, gordura e energia presente no corpo vazio dos bezerros, em função do logaritmo do PCVZ são apresentados na Tabela 1. 
Foi observada regressão linear altamente significativa $(\mathrm{P}<0,01)$ para as equações logarítmicas relativas ao conteúdo corporal de proteína, gordura e energia. Os coeficientes de determinação foram bastante elevados, sendo superiores aos encontrados por Gonçalves et al. (1991), que obtiveram $r^{2}$ de $28,13 \%$ para proteína e $84,83 \%$ para gordura, com novilhos Holandês dos 150 aos 450 kg de PV e semelhantes aos resultados de Rocha (1997), o qual obteve $\mathrm{r}^{2}$ de $99 \%$ para proteína, $91 \%$ para gordura e 96\% para energia, trabalhando com novilhos da raça Holandês dos 150 aos $350 \mathrm{~kg}$ de PV. A equação logarítmica do conteúdo corporal de proteína obtida por Rocha (1997), como no presente estudo, apresentou um melhor ajuste que as equações relativas aos demais nutrientes. Os animais envolvidos em ambos experimentos apresentavam um crescimento muscular elevado.

A partir das equações logarítmicas de regressão constantes na Tabela 1, foram obtidas as equações (Tabela 2) que permitem a estimativa da exigência líquida de proteína e energia ou conteúdo de gordura no ganho de $1 \mathrm{~kg}$ de PCVZ (GPCVZ), para animais de diferentes PCVZ, dentro do intervalo de peso adotado.

Consta na Tabela 3 o conteúdo corporal de proteína e gordura em g/kg de PCVZ e de energia em Mcal/kg de PCVZ, bem como as quantidades desses nutrientes em g/kg e Mcal/kg no ganho de peso corporal vazio

Tabela 1 - Parâmetros das equações de regressão do logaritmo dos conteúdos de proteína $(\mathrm{kg})$, gordura (kg) e energia (Mcal) no corpo vazio, em função do logaritmo do peso do corpo vazio $(\mathrm{kg})$ de bezerros holandeses do nascimento aos 110 dias de idade

Table 1 - Parameters of the regression equations of protein $(\mathrm{kg})$, fat $(\mathrm{kg})$ and energy (Mcal) logarithm content in the empty body in according to the empty body weight logarithm $(\mathrm{kg})$ of dairy calves at newly born to 110 days of age

\begin{tabular}{lccc}
\hline $\begin{array}{l}\text { Nutriente } \\
\text { Nutrient }\end{array}$ & \multicolumn{2}{c}{$\begin{array}{c}\text { Parâmetros } \\
\text { Parameter }\end{array}$} & $\mathrm{r}^{2}(\%)$ \\
\cline { 2 - 3 } & $\begin{array}{c}\text { Intercepto (a) } \\
\text { Intercept }\end{array}$ & $\begin{array}{c}\text { Coeficiente(b) } \\
\text { Coefficient }\end{array}$ \\
\hline $\begin{array}{l}\text { Proteína (kg) } \\
\text { Protein }\end{array}$ & $-0,946233$ & 1,134515 & $98,10^{* *}$ \\
$\begin{array}{l}\text { Gordura (kg) } \\
\text { Fat }\end{array}$ & $-2,841800$ & 1,990358 & $95,94^{* *}$ \\
$\begin{array}{l}\text { Energia(Mcal) } \\
\text { Energy }\end{array}$ & $-0,509414$ & 1,442229 & $97,85^{* *}$ \\
** (P<0,01). & & & \\
\hline
\end{tabular}

(GPCVZ), obtidos para o intervalo de PCVZ de 27,57 a $74,27 \mathrm{~kg}$, a partir das equações mostradas nas Tabelas 1 e 2.

Conforme se elevou o PCVZ de 27,57 para 74,24, ocorreu acréscimo de 12,48\% no conteúdo corporal de proteína. A composição protéica do ganho corporal apresentou o mesmo comportamento. A composição em proteína do ganho de peso foi superior à composição do corpo em $11,85 \%$, sendo este valor requerido para aumentar a composição do corpo em um quilograma. Tal resultado, de incremento protéico da composição corporal e do ganho de peso à medida que aumenta o PCVZ, em um primeiro momento parece contrariar a literatura, mas, analisando-se mais amplamente a questão, verifica-se um comportamento normal, uma vez que os animais em questão encontravam-se em pleno pico de crescimento (do nascimento até os 110 dias de idade).

O requerimento protéico para um bezerro de $34,24 \mathrm{~kg}$ de PCVZ ganhar um $\mathrm{kg}$ de peso corporal foi $5,94 \%$ superior ao do animal pesando $27,57 \mathrm{~kg}$ de PCVZ, enquanto que a diferença para um bezerro de $74,27 \mathrm{~kg}$ de PCVZ ganhar um kg de corpo foi apenas $2,89 \%$ superior ao do animal pesando $67,60 \mathrm{~kg}$ de PCVZ. Tais constatações demonstram um comportamento linear positivo, mas com acréscimos decrescentes para o requerimento protéico, quando o PCVZ se elevou até $74,27 \mathrm{~kg}$.

Tabela 2 - Equações de predição do conteúdo de gordura (g) no ganho de peso corporal e das exigências líquidas proteína (g) e energia (Mcal) por kg de ganho de peso de corpo vazio (GPCVZ), em função do peso de corpo vazio (PCVZ) em kg

Table 2 - Prediction equations of fat $(\mathrm{g})$ content in the body weight gain and net requirement of protein $(g)$ and energy (Mcal) for $\mathrm{kg}$ of empty body weight gain (EBWG) in according to the empty body weight $(E B W)$ in $\mathrm{kg}$

\begin{tabular}{ll}
$\begin{array}{l}\text { Nutriente } \\
\text { Nutrient }\end{array}$ & \multicolumn{1}{c}{$\begin{array}{c}\text { Equações } \\
\text { Equations }\end{array}$} \\
\hline $\begin{array}{l}\text { Proteína (g) } \\
\text { Protein }\end{array}$ & $\mathrm{Y}=1,134515.10^{-0,946233}$ \\
& PCVZ 0,134515 \\
Gordura (g) & $\mathrm{Y}=1.990358 .10^{-2.841800}$ \\
Fat & $\mathrm{PCVZ} \mathrm{0,990358}$ \\
& EBW \\
Energia (Mcal) & $\mathrm{Y}=1,442229.10^{-0,509414}$ \\
Energy & $\mathrm{PCVZ} \mathrm{0,442229}$ \\
& EBW \\
\hline
\end{tabular}


Signoretti et al. (1999), trabalhando com bezerros da raça Holandês submetidos a níveis crescentes de volumoso na dieta, na faixa de peso dos 62,78 aos $260,70 \mathrm{~kg}$ de PCVZ encontraram um aumento no requerimento protéico para os níveis de 10 e 55 \% de volumoso, bem como para a equação geral (ajustada para todos os níveis de volumoso). Os valores do requerimento protéico encontrado pelos referidos autores aumentaram de 179,84 para 183,20 g/kg GPCVZ, quando o PCVZ elevou-se de 62,78 até $260,70 \mathrm{~kg}$, respectivamente. Um comportamento semelhante foi obtido por Araújo (1997), que observou um aumento no requerimento protéico para níveis de 40 e 55\% de volumoso na dieta de animais mestiços (Holandês x zebu), quando a faixa de peso variou de 42,94 a 275,41 kg de PCVZ.

Vasconcelos et al. (1997) atribuem a animais jovens uma exigência protéica proporcional elevada, pois encontram-se em pleno desenvolvimento corporal.

Analisando-se os valores relativos ao conteúdo de gordura e requerimentos energéticos, verifica-se (Tabela 3) que os conteúdos de gordura corporal e do ganho de peso de corpo vazio (GPCVZ) aumentaram com o incremento do peso corporal. Da mesma forma, o conteúdo corporal de energia e as exigências líquidas de energia para GPCVZ aumentaram conforme o incremento de PCVZ de 27,57 até 74,27 kg. Esses resultados concordam com os obtidos por Salvador (1980), Gonçalves et al. (1991), Almeida (1995), Boin (1995), Fontes (1995), Rocha (1997), Backes (1998), Ferreira et al. (1999), Véras et al. (2000) e Zervoudakis et al. (2000), os quais trabalharam com bovinos de diversas categorias e encontraram valores crescentes para os requerimentos energéticos à medida que os pesos vivo e corporal aumentaram.

A composição de gordura no GPCVZ e as exigências líquidas de energia para GPCVZ encontrados por Signoretti et al. (1999) para bezerros da raça Holandês com 62,78 kg de PCVZ foram, respectivamente, 101,94 g/kg de GPCVZ e 2,01 Mcal/kg de GPCVZ, valores esses inferiores aos encontrados no presente estudo.

Na Tabela 4 encontram-se os resultados referentes à composição de gordura (g/kg de GPV) do ganho de peso e às exigências líquidas de proteína $(\mathrm{g} / \mathrm{kg}$ de GPV) e energia (Mcal/kg de GPV), para o intervalo de peso vivo de 30 a $100 \mathrm{~kg}$.

O FC obtido no presente experimento (PV/PCVZ) apresentou um valor médio de 1,25, na faixa de peso e condições estudadas. Entretanto, observou-se que, à medida que se elevou o PV, a relação PV/PCVZ também se elevou, devido ao enchimento do trato gastrintestinal com a elevação do PV dos bezerros.

Os requerimentos líquidos de proteína para ganho de peso vivo (GPV) decresceram com a elevação do

Tabela 3 - Conteúdo de proteína (g), gordura (g) e energia (Mcal) por kg de peso corporal vazio (PCVZ) e exigência líquida de proteína (g), gordura (g) e energia (Mcal) por kg de ganho de peso de corpo vazio (GPCVZ) de bezerros machos Holandês, do nascimento aos 110 dias de idade

Table 3 - Protein (g), fat $(\mathrm{g})$ and energy (Mcal) content for $\mathrm{kg}$ the empty body weight (EBW) and net requirement of protein ( $\mathrm{g}$ ), fat (g) and energy (Mcal) for $\mathrm{kg}$ of empty body weight gain (EBWG) of dairy male calves at newly born to 110 days of age

\begin{tabular}{|c|c|c|c|c|c|c|c|}
\hline \multirow{6}{*}{$\begin{array}{l}\text { PV } \\
L W\end{array}$} & \multirow{6}{*}{$\begin{array}{l}\text { PCVZ } \\
E B W\end{array}$} & \multicolumn{6}{|c|}{$\begin{array}{c}\text { Nutriente } \\
\text { Nutrient }\end{array}$} \\
\hline & & \multirow{2}{*}{\multicolumn{2}{|c|}{$\begin{array}{c}\text { Proteína } \\
\text { Protein }\end{array}$}} & \multirow{2}{*}{\multicolumn{2}{|c|}{$\begin{array}{c}\text { Gordura } \\
\text { Fat }\end{array}$}} & \multirow{2}{*}{\multicolumn{2}{|c|}{$\begin{array}{c}\text { Energia } \\
\text { Energy }\end{array}$}} \\
\hline & & & & & & & \\
\hline & & $\mathrm{g} / \mathrm{kg}$ & g/kg & $\mathrm{g} / \mathrm{kg}$ & g/kg & Mcal/kg & Mcal/kg \\
\hline & & PCVZ & GPCVZ & PCVZ & GPCVZ & PCVZ & GPCVZ \\
\hline & & $E B W$ & $E B W G$ & $E B W$ & $E B W G$ & $E B W$ & $E B W G$ \\
\hline 30 & 27,57 & 176,82 & 200,60 & 38,44 & 76,51 & 1,34 & 1,93 \\
\hline 40 & 34,24 & 182,05 & 206,54 & 47,64 & 94,82 & 1,48 & 2,13 \\
\hline 50 & 40,91 & 186,46 & 211,54 & 56,82 & 113,10 & 1,60 & 2,30 \\
\hline 60 & 47,58 & 190,29 & 215,88 & 65,99 & 131,35 & 1,71 & 2,46 \\
\hline 70 & 54,26 & 193,68 & 219,73 & 75,15 & 149,57 & 1,81 & 2,61 \\
\hline 80 & 60,93 & 196,72 & 223,18 & 84,29 & 167,77 & 1,90 & 2,75 \\
\hline 90 & 67,60 & 199,49 & 226,32 & 93,43 & 185,96 & 1,99 & 2,88 \\
\hline 100 & 74,27 & 202,03 & 229,21 & 102,56 & 204,12 & 2,08 & 2,99 \\
\hline
\end{tabular}


peso vivo (PV). Para bezerros de $30 \mathrm{~kg}$ aumentarem para 31 kg de PV, a exigência líquida obtida foi 184,36 $\mathrm{g} / \mathrm{kg}$ de GPV e para animais de $100 \mathrm{~kg}$ aumentarem para $101 \mathrm{~kg}$ de PV foi 170,23 g/kg GPV. Esse decréscimo de 7,66 \% no requerimento líquido de proteína, quando o PV elevou-se de 30 para $100 \mathrm{~kg}$ deve-se, em parte, pela diluição do peso vivo. O que pode ser comprovado pelo aumento do quociente PV/ PCVZ, que variou de 1,09 até 1,35, quando o PV e PCVZ elevaram-se de 30 e 27,57 kg para 100 e 74,27 $\mathrm{kg}$, respectivamente.

Em um experimento conduzido com novilhos da raça Holandês, Gonçalves et al. (1991) obtiveram uma exigência líquida de proteína de 206 g/kg GPV para animais com $150 \mathrm{~kg}$ de PV. Já os dados de Almeida et al. (1999), com um FC de 1,29; indicam uma exigência líquida para GPV de 153,97 g de proteína, para novilhos cruzados (Holandês x Gir) com 150 kg de PV e $116 \mathrm{~kg}$ de PCVZ. A exigência líquida obtida no presente estudo (170,23 g/kg GPV) para animais com $100 \mathrm{~kg}$ de $\mathrm{PV}$, situa-se em uma posição intermediária às anteriormente citadas, aproximando-se dos 153,97 g/kg de GPV obtidos por Almeida et al. (1999) e ficando aquém aos dados de Gonçalves et al. (1991).

A quantidade de gordura no GPV, bem como o requerimento líquido de energia para GPV aumentou de acordo com o aumento de PV dos animais. Quando o PV se elevou de 30 para $100 \mathrm{~kg}$ (faixa de $70 \mathrm{~kg}$ ) a quantidade de gordura requerida para o GPV sofreu acréscimo de 54\%, passando de 70,32 para $151,60 \mathrm{~g} / \mathrm{kg}$ de GPV. Da mesma maneira, o requerimento líquido de energia foi acrescido de $20 \%$, elevando-se de 1,77 para 2,22 Mcal/kg de GPCVZ. Analisando-se os dados obtidos por Araújo et al. (1998) encontra-se um acréscimo de 35,62 \% para gordura e de $22 \%$ para energia, quando se estima o requerimento líquido de GPV desses nutrientes, quando o peso vivo aumenta de 60 para $100 \mathrm{~kg}$. A exigência de energia líquida para GPV estimada, foi inferior ao requerimento estimado no presente estudo.

O valor da exigência líquida de energia para GPV, estimada pelo AFRC (1993) para bezerros da raça Holandês com $30 \mathrm{~kg}$ de PV é de 1,22 Mcal/kg de GPV. Já o NRC (1988) estima um valor 8\% superior para suprir a mesma exigência, sendo de 1,32 Mcal/kg de GPV. Tais valores, preconizados pelos referidos comitês, são inferiores aos obtidos no presente estudo. A exigência líquida de energia estimada nessa pesquisa para bezerros Holandês de $30 \mathrm{~kg}$ de PV (1,77 Mcal/kg GPV) é 25\% maior que o preconizado pelo NRC (1988) e 31\% maior que o recomendado pelo AFRC (1993).

Recomenda-se a condução de mais estudos nesta área, principalmente com animais em crescimento, enquadrados em faixas de peso com limite superior não muito elevados, objetivando-se o conhecimento e esclarecimento de questões ainda em aberto.

Tabela 4 - Composição do ganho de peso vivo em gordura (g) e exigências líquidas de proteína (g) e energia (Mcal) por $\mathrm{kg}$ de ganho de peso vivo (GPV) de bezerros machos Holandês, do nascimento aos 110 dias de idade

Table 4 - Live weight gain content of fat $(g)$ and net requirement of protein $(g)$, and energy (Mcal) for kg of live weight gain (LWG) of dairy male calves at newly born to 110 days of age

\begin{tabular}{lccc}
\hline PV & \multicolumn{3}{c}{$\begin{array}{c}\text { Nutriente } \\
\text { Nutrient }\end{array}$} \\
\cline { 2 - 4 } & $\begin{array}{c}\text { Proteína }(\mathrm{g} / \mathrm{kg} \mathrm{GPV}) \\
\text { Protein }(\mathrm{g} / \mathrm{kg} \text { LWG) }\end{array}$ & $\begin{array}{c}\text { Gordura }(\mathrm{g} / \mathrm{kg} \mathrm{GPV}) \\
\text { Fat }(\mathrm{g} / \mathrm{kg} L \text { WG })\end{array}$ & $\begin{array}{c}\text { Energia }(\text { Mcal } / \mathrm{kg} \mathrm{GPV}) \\
\text { Energy }(\text { Mcal/kg } L W G)\end{array}$ \\
\hline 30 & 184,36 & 70,32 & 1,77 \\
40 & 176,81 & 81,17 & 1,82 \\
50 & 173,09 & 92,55 & 1,88 \\
60 & 171,21 & 104,17 & 1,95 \\
70 & 170,31 & 115,93 & 2,02 \\
80 & 169,97 & 127,77 & 2,09 \\
90 & 169,98 & 139,67 & 2,16 \\
100 & 170,23 & 151,60 & 2,22 \\
\hline
\end{tabular}




\section{Conclusões}

Do nascimento até os 110 dias de idade ocorre um incremento de proteína, gordura e energia na composição do corpo vazio dos bezerros machos da raça Holandês.

À medida que os bezerros se desenvolvem até os 110 dias de idade, ocorre um acréscimo nas exigências líquidas de proteína e de energia para ganho de peso corporal.

As exigências líquidas de proteína para ganho corporal aumentaram de 200,60 para 229,21 g/kg GPCVZ, quando o peso vivo dos animais aumentou de 30 para $100 \mathrm{~kg}$.

As exigências líquidas de energia para ganho corporal aumentaram de 1,93 para 2,99 Mcal/kg GPCVZ, quando o peso vivo dos animais aumentou de 30 para $100 \mathrm{~kg}$.

\section{Literatura Citada}

AGRICULTURAL AND FOOD RESEARCH COUNCIL AFRC. Energy and protein requirements of ruminants. Oxon: CAB International, 1993. 159p.

AGRICULTURAL RESEARCH COUNCIL - ARC. The nutrient requeriments of farm livestock. England: Commonwealth Agriculture Bureaux, 1980. 350p.

ALMEIDA, S.R.S. Desempenho e exigências líquidas de energia e proteína de novilhos de dois grupos genéticos terminados em confinamento. Santa Maria: Universidade Federal de Santa Maria, 1995. 76p. Dissertação (Mestrado em Zootecnia) - Universidade Federal de Santa Maria, 1995.

ALMEIDA, M.I.V.; FONTES, C.A.A.; CAMPOS, O.F. et al. Exigências líquidas de energia e proteína de novilhos mestiços em ganho compensatório. In: REUNIÃO ANUAL DA SOCIEDADE BRASILEIRA DE ZOOTECNIA, 36., 1999, Porto Alegre. Anais ... Porto Alegre: Sociedade Brasileira de Zootecnia, 1999. p.305.

ARAÚJO, G.G.L. Consumo, digestibilidade, desempenho, composição corporal e exigências nutricionais de bezerros alimentados com dietas contendo diferentes níveis de volumoso. Viçosa, MG: Universidade Federal Viçosa, 1997. 107p. Tese (Doutorado em Zootecnia) Universidade Federal Viçosa, 1997.

ARAÚJO, G.G.L.; SILVA, J.F.C.; VALADARES FILHO, S.C. et al. Composição corporal e exigências líquidas de energia. In: REUNIÃO ANUAL DA SOCIEDADE BRASILEIRA DE ZOOTECNIA, 35., 1998, Botucatu. Anais ... Botucatu: Sociedade Brasileira de Zootecnia, 1998. p.332-334.

BACKES, A.A. Desempenho, composição corporal, exigências nutricionais e validação de diferentes sistemas de arraçoamento para novilhos confinados. Santa Maria: Universidade Federal de Santa Maria, 1998. 160p. Dissertação (Mestrado em Zootecnia) - Universidade Federal de Santa Maria, 1998.

BERG, R.T.; BUTTERFIELD, R.M. New concepts of cattle growth. New York: Sydney University, 1976. 240p.

BLAXTER, K.L. Metabolismo energético de los ruminantes. Zaragoza: Acribia, 1964. 314p.

BOIN, C. Alguns dados sobre exigências de energia e de proteína de zebuínos. In: SIMPÓSIO INTERNACIONAL SOBRE EXIGÊNCIAS NUTRICIONAIS DE RUMINANTES, 1995, Viçosa, MG. Anais ... Viçosa: Universidade Federal de Viçosa, 1995. p.457-465.

COELHO DA SILVA, J.F. Exigências de macroelementos inorgânicos para bovinos: O sistema ARC/AFRC e a experiência no Brasil. In: SIMPÓSIO INTERNACIONAL SOBRE EXIGÊNCIAS NUTRICIONAIS DE RUMINANTES, 1995, Viçosa, MG. Anais ... Viçosa: Universidade Federal de Viçosa, 1995. p.467-504.

DI MARCO, O.N. Crescimiento y respuesta animal. Balcarce: Associación Argentina de Producción Animal, 1994. 129p.

FERREIRA, M.A.; VALADARES FILHO, S.C.; COELHO DA SILVA, J.F. et al. Composição corporal e exigências líquidas de proteína e energia para ganho de peso de bovinos F1 Simental x Nelore. Revista Brasileira de Zootecnia, v.28, n.2, p.352-360, 1999.

FERRELL, C.L.; JENKINS, T.G. Body composition and energy utilization by steers of diverse genotypes fed a hig-concentrate diet during the finishing period: II- Angus, Boran, Brahman, Hereford and Tuli Sires. Journal of Animal Science, v.76, n.1, p.647-657, 1998.

FONTES, C.A.A. Composição corporal, exigências líquidas de nutrientes para ganho de peso e desempenho produtivo de animais zebuínos e mestiços europeu-zebú - Resultados experimentais. In: SIMPÓSIO INTERNACIONAL SOBRE EXIGÊNCIAS NUTRICIONAIS DE RUMINANTES, 1995, Viçosa, MG. Anais ... Viçosa: Universidade Federal de Viçosa, 1995. p.419-456.

FOX, D.G.; BLACK, J.R. System for predicting body composition and performance of crowing cattle. Journal of Animal Science, v.58, n.3, p.725-739, 1984.

GONÇALVES, L.C.; COELHO DA SILVA, J.F.; VALADARES FILHO, S.C. Composição do ganho em peso de taurinos, zebuínos, seus mestiços e bubalinos. Revista da Sociedade Brasileira de Zootecnia, v.20, n.4, p.413-419, 1991.

KLEIBER, M. Bioenergetica animal - El fuego de la vida. Zaragoza: Acribia, 1972. 428p.

KOCK, S.W.; PRESTON, R.L. Estimation of bovine carcass composition by the urea diluition techinique. Journal of Animal Science, v.48, n.2, p.319, 1979.

LUCCI, C.S. Bovinos leiteiros jovens. São Paulo: Nobel, 1989. 371p.

MAYNARD, L.; LOOSLI, J.; HENTZ, H. et al. Nutrição animal. Rio de Janeiro: Freitas Bastos S.A., 1984. 726p.

NATIONAL RESEARCH COUNCIL - NRC. Nutrient requeriments of dairy cattle. 6.ed. Washington, D.C.: National Academy of Science, 1988. 157p.

NATIONAL RESEARCH COUNCIL - NRC. Nutrient requeriments of beef cattle. 7.ed. Washington, D.C.: National Academy of Science, 1996. 242p.

ROCHA, E.O. Estudo do desaleitamento precoce, exigências nutricionais e características produtivas de bovinos de origem leiteira, para corte. Viçosa, MG: Universidade Federal Viçosa, 1997. 151p. Tese (Doutorado em Zootecnia) - Universidade Federal Viçosa, 1997.

ROCHA, E.O.; FONTES, C.A.A. Composição corporal, composição do ganho de peso e exigências nutricionais de novilhos de origem leiteira. Revista Brasileira de Zootecnia, v.28, n.1, p.159-168, 1999. 
SALVADOR, M. Exigências de energia e proteína para engorda de novilhos azebuados. Viçosa, MG: Universidade Federal Viçosa, 1980. 70p. Dissertação (Mestrado em Zootecnia) - Universidade Federal Viçosa, 1980.

STATISTICAL ANALYSIS SYSTEM - SAS. User's guide: Stactistcs. Version 6.11. Cary: 1996.

SIGNORETTI, R.D.; COELHO DA SILVA, J.F.; VALADARES FILHO, S.C. et al. Composição corporal e exigências líquidas de energia e proteína de bezerros da raça holandesa alimentados com dietas contendo diferentes níveis de volumoso. Revista Brasileira de Zootecnia, v.28, n.1, p.195-204, 1999.

SILVA, D.J. Análise de alimentos: métodos químicos e biológicos. Viçosa, MG: Universidade Federal Viçosa, 1990. 165p.

TEIXEIRA, J.C. Exigências de energia e proteína, composição e área corporal e principais cortes da carcaça em seis grupos genéticos de bovídeos. Viçosa, MG: Universidade Federal Viçosa, 1984. 94p. Tese (Doutorado em Zootecnia) - Universidade Federal Viçosa, 1984.

VASCONCELOS, V.R.; RESENDE, K.T.; PIMENTEL, J.C. et al. Cinética de degradação ruminal da proteína de forrageiras do Semi-árido brasileiro em caprinos. In: REUNIÃO ANUAL DA SOCIEDADE BRASILEIRA DE ZOOTECNIA, 34., 1997, Juiz de Fora. Anais ... Juiz de Fora: Sociedade Brasileira de Zootecnia, 1997. p.478-480.
VÉRAS, A.S.C.; VALADARES FILHO, S.C.; COELHO DA SILVA, J.F. et al. Predição da composição corporal de bovinos não-castrados, alimentados com rações contendo diferentes níveis de concentrado. In: REUNIÃO ANUAL DA SOCIEDADE BRASILEIRA DE ZOOTECNIA, 37., 2000, Viçosa, MG. Anais ... Viçosa: Sociedade Brasileira de Zootecnia, 2000. p.473.

ZERVOUDAKIS, J.T.; PAULINO, M.F.; DETMANN, E. et al. Exigências líquidas de proteína e energia de novilhos suplementados no período das águas. In: REUNIÃO ANUAL DA SOCIEDADE BRASILEIRA DE ZOOTECNIA, 37., 2000. Viçosa, MG. Anais ... Viçosa: Sociedade Brasileira de Zootecnia, 2000. p.445.

Recebido em: 13/09/02

Aceito em: 13/12/02 